\title{
Italian-German bilinguals: The effects of heritage language use on accent in early-acquired languages
}

International Journal of Bilingualism 2020, Vol. 24(2) 289-304 (C) The Author(s) 2019

Article reuse guidelines: sagepub.com/journals-permissions DOI: 10.1 | 77//3670069|9826867 journals.sagepub.com/home/ijb

(S)AGE

\section{Anika Lloyd-Smith and Marieke Einfeldt}

Department of Linguistics, University of Konstanz, Germany

\section{Tanja Kupisch}

Department of Linguistics, University of Konstanz, Germany;

Department of Languages and Culture, The Arctic University of Norway, Norway

\begin{abstract}
Aims and objectives/purpose/research questions: This study investigates perceived accent in the two early-acquired languages of $2 \mathrm{I}$ adult-aged bilinguals with Italian as the heritage language $(\mathrm{HL})$ and German as the majority language $(\mathrm{ML})$. We test the relative ability of 'age of onset (AoO) in German' (range $=0-6$ years) and 'Italian use' to predict perceived nativeness in Italian and German.

Design/methodology/approach: Two accent rating experiments were carried out (one in each language) comparing the bilingual speech samples to those of monolingual and second language (L2) control groups. The samples were rated by German and Italian-speaking judges for foreign accent ('yes' or 'no') and for degree of certainty ('certain, 'semi-certain', 'uncertain').

Data and analysis: The effects of 'AoO in German' and 'Italian Use' (operationalized as an Italian Use Score) were analysed using correlational analyses and logistic regression.

Findings/conclusions: Our results show that almost all bilinguals were indistinguishable from monolingual controls in German, and that their perceived accent in Italian lay somewhere between that of the monolingual and L2 controls. Based on regression analyses, we conclude that a later introduction of the ML has neither a negative effect on the ML itself, nor does it show up advantages in the HL. Instead, how native-like the heritage speakers (HSs) sound in the HL largely depends on HL use. No negative effects of HL use are found for German.

Originality: We test a new population of Italian HSs in South Germany and compare these results to findings from other HS populations in Germany.

Significance/implications: This study shows that, although it may be the case for child-aged bilinguals that introducing the ML earlier causes more phonological pressure on the $\mathrm{HL}$, this effect seems to have disappeared by adulthood - at least with regards to perceived global accent. Also, accent in the $\mathrm{HL}$ depends on $\mathrm{HL}$ use across the lifespan.
\end{abstract}




\section{Keywords}

Heritage speakers, foreign accent, age of onset, input and use, German, Italian

\section{Introduction}

In the past, much attention has been given to the effect of age of onset (AoO) on the attainment of native-like speech, with studies showing that perceived nativeness decreases with a later AoO (Abrahamsson \& Hyltenstam, 2009; Flege, Munro, \& Mackay, 1995). The study of heritage speakers (HSs) provides an interesting case, since HSs have acquired their heritage language (HL) from birth, and often acquire the majority language (ML) as an early second language (L2). One view is that, given exposure from birth or from very early on, HSs will learn to speak both their languages without a detectable accent, consistent with traditional accounts of the critical period hypothesis. However, the literature on HL phonetics and phonology has already demonstrated that HSs differ at the level of perception and production from monolingual speakers (e.g., Chang \& Yao, 2016; Chang, Yao, Haynes \& Rhodes, 2011), although they consistently outperform L2 learners. To date, there exist only a few studies that examine perceived foreign accent in both HSs' early-acquired languages. The results of these studies indicate HSs are often perceived as non-accented in their ML, and as accented in their HL (e.g., Kupisch et al., 2014; Lein, Kupisch, \& van der Weijer, 2016; Stangen, Kupisch, Proietti Erguen \& Zielke, 2015). Thus, exposure to the HL from birth does not guarantee accent-free speech and, by the same token, the potential effects of a later AoO in the ML are mostly overcome by adulthood. Further, some studies have indicated that later exposure to the ML may be indirectly beneficial for HL outcomes, since the HL then has more time to develop without pressure from another phonological system (e.g., Flores \& Rato, 2016). However, what is often interpreted as an effect of AoO is, arguably, more likely due to the increased exposure and use that goes hand-in-hand with acquiring only one language during the first years of life. This study, therefore, aims to tease apart the relative role of 'HL use' and 'AoO in the ML' for outcomes in adult HSs' two early-acquired languages, Italian and German.

The speakers in the present are early bilingual speakers of Italian and German, and they are also HSs of Italian, since Italian was acquired naturalistically from one or both parents and is not the language of the larger national society. Further, these speakers are either simultaneous bilinguals (2L1s) who acquired both German and Italian from birth, or successive bilinguals (eL2s) whose first intensive contact with German occurred between ages 3 and 6. Our monolingual controls are not monolingual in a functional sense -they are late L2 learners of other languages - but grew up speaking only German in Germany, or Italian in Italy.

\section{Phonological acquisition in heritage speakers, age of onset and language use}

It has often been suggested that children pass through a 'sensitive period' earlier for phonology than for other language domains, such as morphosyntax. Bever (1981, p. 195) postulated that, in contrast to syntactic and semantic acquisition, which continues into adolescence, children acquire their phonological system during early childhood, resulting in the comparatively early dismantlement of the mechanisms required for phonological acquisition. Paradis (2009, pp. 113-114) extended this argument to the notions of procedural versus declarative learning, suggesting that, due to cognitive constraints, children exposed to input before age 4 acquire language implicitly, using procedural memory, while acquisition after this age relies on declarative memory. Since phonology is viewed here to be subserved by procedural memory, the optimal period is surpassed 
earlier for phonological acquisition than for other domains. Some evidence for a sensitive period around age 4 has been found, for example, by Flege et al. (1995), who showed that discerning listeners were able to detect foreign accents in the English of L1 Italian speakers with an AoO as early as 3;1 years. For most listeners, however, accents were not detectable until 7;4 years, in line with a study that looked at (early) L2 learners' vowel production (Munro, Flege, \& Mackay, 1996), for whom accents were not detected until 7;5 years. Nonetheless, it is conceivable based on these findings that HSs might retain a foreign accent in the ML if it is acquired after age 3.

In reality, results from studies that focus on aspects of HL pronunciation vary across populations and individuals, and do not allow for generalization. Differential effects of $2 \mathrm{~L} 1$ and eL2 acquisition were found by Sundara and Polka (2008), who reported that simultaneous Canadian-French bilinguals were able to discriminate between the Canadian-French dental /d/ and Canadian-English alveolar /d/, while eL2s (exposed to Canadian-French from age 5 in immersion programmes) treated this as a merged category. In contrast, Lein et al. (2016) and Nagy and Kochetov (2013) demonstrated monolingual-like voice onset time (VOT) for voiceless stops in French and Italian HSs, while Nagy and Kochetov (2013) found different patterns for the same sounds in comparable populations of Russian and Ukrainian HSs. Kupisch and Lleó (2017) report individual variation in the production of Italian voiceless stops in both HSs of German in Italy and HSs of Italian in Germany, arguing that markedness plays a role. They found that differences to monolingual baselines were more obvious in German, which has long lag VOT, than in Italian, which has short lag VOT, and long lag VOT is more marked than short lag VOT. For global pronunciation, Kupisch et al. (2014) showed that most HSs have perceived foreign accents in their HL, although not in their ML. Similar results were reported by Stangen et al. (2015) for heritage Turkish.

The idea that an early AoO guarantees monolingual-like pronunciation later in life is challenged by the observation that phonological acquisition is by no means complete as early as assumed. Research in child phonology suggests that (i) for specific properties, there may be a long time lag between first appearance and adult-like production, (ii) there are early-acquired properties (appearing within the first two years) and late-acquired properties (mastered only after school entry) and (iii) acquisition patterns are language specific. This means that, by the time child HSs are massively exposed to the ML, not all phonological knowledge has been stabilized. While properties may already be in place by the time exposure to the ML starts, late-acquired properties are still in the process of developing, thus being more vulnerable to influence from the other language. Finally, even if early-acquired properties are more likely to be preserved, they may still undergo influence from the speaker's other language. Therefore, it should not surprise us too much if HSs end up having a foreign accent.

We provide a few examples for the extended process of phonological acquisition in what follows. Length distinction in vowels and consonants is early acquired. Vowel length distinctions in German appear from early on and adult-like contrasts are established by 2;6 (Kehoe \& Lleó, 2003). Children acquiring Finnish, which has consonant gemination, begin to align their consonantal length during the 50-word phase (Kunnari, Nakai, \& Vihman, 2001), although target-like durations emerge only gradually with a growing lexicon and the maturation of motor skills (e.g., Khattab \& Al-Tamimi, 2015). By contrast, the acquisition of stop consonants is a very prolonged process, determined by articulatory challenges. Children acquiring aspiration languages can realize short lag VOT and start distinguishing voiced from voiceless sounds by age 2 , but where prevoicing the most marked of VOT categories - is required, non-target-like productions persist into school age (Stoehr, 2018, p. 34). The production of the fricatives [s] and [z] deviates from the target until $5 ; 5$ and is still not stable at 10;0 (Fox, 2007). Finally, properties of the target language play a crucial role. For instance, the age at which children produce target-like syllable codas is determined by their frequency. German is a language with complex syllable structure; children's first words 
contain codas (e.g., Grijzenhout \& Joppen-Hellwig, 2002) and coda production is almost complete by the age of 2;1-2;4 (Lleó, 2003). However, in Spanish, a language with less complex syllables, children's first words (ages 1;1-1;6) contain hardly any codas and the percentage is still low at age 2;1-2;4 (Lleó, 2003). Another example concerns rhythm. The rhythmic pattern of syllable-timed languages is considered less complex than that of stressed-timed rhythm. In line with this assumption, Grabe, Post, and Watson (1999) found that the rhythmic patterns of French-learning children at age 4 did not differ significantly from that of their mothers, while those of age-matched English children were significantly different. These examples indicate that the suggestion of a particular critical age for phonological acquisition could not be justified based on facts from language acquisition studies.

A common finding for HSs in their HL is that 'later is better' when it comes to introducing the ML. Yeni-Komshian, Flege, and Liu (2000) showed that a later AoO in English correlated positively with Korean speakers' pronunciation in their first language (L1) Korean. Similarly, Ahn, Chang, DeKeyser, and Lee-Ellis (2017) showed that the earlier L1 Korean speakers were exposed to English as an early L2, the less able they were to perceive L1-specific contrasts in Korean. The implication from these studies is that a later AoO permits an increased state of development of the L1 phonetic-phonological system - a process that coincides with, but is arguably not caused by, increasing age. Instead, it seems more likely that such findings can be better explained by the increased use of the HL that results from exposure to just one language early in life. Potential effects of HL use for perceived accent in the HL were found by Kupisch et al. (2014), who investigated perceived accent in 38 adult 2L1 speakers (German-French and German-Italian). In their results, the HSs of French in Germany were rated as non-accented in $49 \%$ of ratings, and the HSs of German in Italy in just 7\% of ratings. The background variables 'language use' and 'length of residence in the HL country' were found to correlate the most strongly with perceived nativeness, suggesting that 'HL use' was the best predictor of perceived nativeness.

Other studies have suggested negative consequences of HL use for accent in the ML. For (e)L2 acquisition, it was shown that Italian immigrants to the USA were more likely to speak English with a detectable accent if they used Italian frequently (Flege, Frieda, \& Nozawa, 1997). Stangen et al. (2015) suspected a similar effect for perceived foreign accent in a group of second-generation Turkish HSs in their ML German. In contrast to the HSs in Kupisch et al. (2014), who were indistinguishable from monolinguals in their ML, those in Stangen et al. (2015) were rated as nonaccented in just $60 \%$ of ratings in their ML. The high degree of Turkish use amongst these speakers could be a possible explanation for two reasons. Firstly, Hamburg, the setting for the study, is home to one of the largest Turkish-speaking communities in Western Europe, and these speakers likely had more opportunities for HL use than those in Kupisch et al. (2014). Secondly, in a follow-up study by Kupisch, Lloyd-Smith, and Stangen (in press), a negative (but weak) correlation between Turkish use and perceived nativeness in German was found in this population. Another explanation put forward by Stangen et al. (2015) to explain these speakers' detectable accent in German is the possibility that some participants spoke German with detectable traces of Kiezdeutsch, a variety of German spoken in multi-ethnic urban environments in Germany. Although by no means restricted to migrant communities (Wiese, 2012), Kiezdeutsch is more often associated with speakers of Turkish than with German-Italian or German-French bilinguals.

The studies outlined above leave open the question of the relative role of HL use, AoO in the ML and contact with non-standard varieties, such as Kiezdeutsch, for perceived accent in HSs' early-acquired languages. This study aims to shed light on these issues by testing a new population, namely Italian-German early bilinguals in Konstanz, a South-German town not usually associated with Kiezdeutsch. In our study, we examine perceived accent in $21 \mathrm{HSs}$ of Italian $(\mathrm{AoO}$ in German $=0-6$ years $)$ in two separate rating experiments: the 
Table I. Overview of bilingual participants $(N=21)$. The information in the last three columns will be explained in the Results section.

\begin{tabular}{|c|c|c|c|c|c|}
\hline Participant & AoO in German & AoO in Italian & $\begin{array}{l}\% \text { rated native in } \\
\text { German }\end{array}$ & $\begin{array}{l}\% \text { rated native in } \\
\text { Italian }\end{array}$ & $\begin{array}{l}\text { Italian Use } \\
\text { Score }\end{array}$ \\
\hline \multicolumn{6}{|c|}{ Simultaneous bilinguals $(2 \mathrm{LI})(n=7)$} \\
\hline B07LIZ & 0 & 0 & 100.00 & 2.13 & 15.00 \\
\hline B08MAR & 0 & 0 & 83.33 & 38.30 & 15.00 \\
\hline BIIANN & 0 & 0 & 93.33 & 6.38 & 10.50 \\
\hline BI5LAU & 0 & 0 & 100.00 & 4.26 & 10.30 \\
\hline B20PAO & 0 & 0 & 96.67 & 0.00 & 13.00 \\
\hline B2ISHA & 0 & 0 & 90.00 & 0.00 & 12.00 \\
\hline B23GIU & 0 & 0 & 100.00 & 78.72 & 16.30 \\
\hline \multicolumn{6}{|c|}{ Successive bilinguals (eL2) $(n=14)$} \\
\hline BOICRI & 3 & 0 & 93.33 & 78.72 & 22.30 \\
\hline B02VAN & 3 & 0 & 73.33 & 72.34 & 20.00 \\
\hline B04GRA & 3 & 0 & 96.67 & 25.53 & 17.50 \\
\hline B05DAV & 3 & 0 & 76.67 & 82.98 & 21.50 \\
\hline BIOFIL & 3 & 0 & 90.00 & 97.87 & 19.00 \\
\hline $\mathrm{BI} 4 \mathrm{OCH}$ & 3 & 0 & 70.00 & 80.85 & 17.00 \\
\hline BI7LOR & 3 & 0 & 96.67 & 57.45 & 15.30 \\
\hline B03ANN & 4 & 0 & 76.67 & 70.21 & 19.00 \\
\hline BI3FRA & 4 & 0 & 96.67 & 46.81 & 19.50 \\
\hline BI6TER & 4 & 0 & 83.33 & 91.49 & 18.80 \\
\hline $\mathrm{BI} 2 \mathrm{GIU}$ & 5 & 0 & 63.33 & 48.94 & 19.00 \\
\hline B22STE & 5 & 0 & 96.67 & 8.51 & 18.50 \\
\hline B06NAD & 6 & 0 & 93.33 & 85.11 & 20.00 \\
\hline B09SAR & 6 & 0 & 76.67 & 91.49 & 22.00 \\
\hline
\end{tabular}

AoO: age of onset.

German-language experiment and the Italian-language experiment. To investigate the role of Italian use, we developed an Italian Use Score (IUS) along the lines of the Turkish Use Score used in Kupisch et al. (in press), and used this score as a continuous predictor in a regression model. Our research questions are the following.

I. To what extent is perceived foreign accent in German and Italian affected by AoO in German?

II. To what extent is perceived foreign accent in German and Italian affected by the amount of Italian use?

\section{Participants and methods}

\section{Speakers}

The speakers included 21 adult-aged Italian-German bilinguals ${ }^{1}$ (mean age $=23$ ), whom we describe in more detail below (see also Table 1). In addition, monolingual and late L2 control groups were included in each experiment. The L2 German controls $(N=10$, mean age $=32)$ were Italian students or researchers living in Germany; the L2 Italian controls $(N=10$, mean age $=28)$ 
(a)

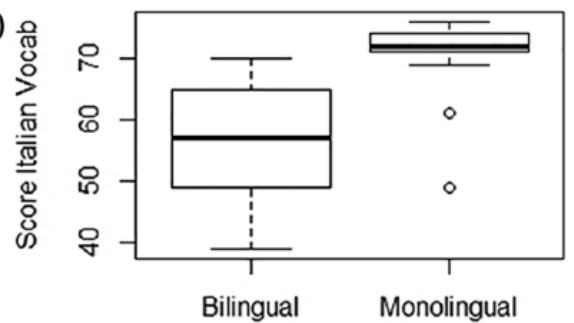

(b)

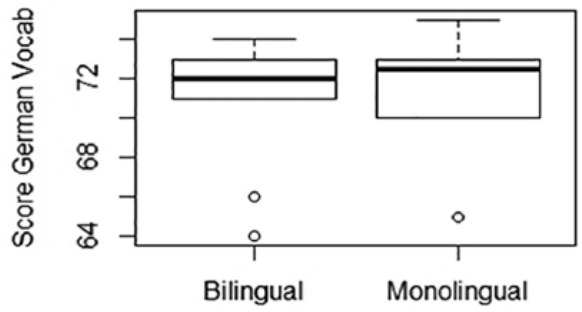

Figure I. Bilingual and monolingual scores in Italian (a) and German (b) vocabulary tasks.

were German students and researchers of Italian linguistics living in Germany. To ensure comparability with the HSs, the L2 controls had a medium to high proficiency, that is, they needed to be able to provide a fluent narration of the picture sequence (see Preparation of material section) lasting at least 1 minute; several speakers were excluded on this basis. The monolingual controls for the German experiment were from South Germany (except for one, who was from the North) and spoke the same variety of German as the bilinguals; the Italian monolingual controls were from North and South Italy, reflecting the diverse regional origins of the bilinguals' parents. ${ }^{2}$

The bilingual participants (Table 1) were born and grew up in South Germany to Italian-speaking parents (first-generation immigrants from North and South Italy). Seven bilinguals were exposed to German from birth and had one Italian and one German-speaking parent (2L1 speakers). Fourteen bilinguals had two Italian-speaking parents and their first intensive contact with German occurred between 3 and 6 years (early L2 learners). ${ }^{3}$ They had all completed their schooling in Germany and were students at a South-German university at the time of testing. Their proficiency was assessed in both languages using a yes/no vocabulary test, which required participants to identify 50 real words (full verbs) and 25 phonotactically plausible pseudo-words (the stimuli were taken from the online DIALANG placement test (Alderson, 2005). As shown in Figure 1, the bilinguals performed on par with the German monolinguals in the German vocabulary test (mean $=70.52, \mathrm{SD}=3.40)$. In the Italian test, their scores display a much larger degree of variation $(\mathrm{M}=$ $58.52, \mathrm{SD}=8.44)$ and none fall within the range of the Italian monolingual controls.

\section{Raters}

There were 30 monolingual German raters for the German experiment, and 47 monolingual Italian raters for the Italian experiment. The German raters were all resident in Germany and included university students $(n=15), \mathrm{PhD}$ candidates and researchers $(n=12)$ and others $(n=3)$. The Italian raters were from northern $(n=22)$ and central-southern Italy $(n=25)$ and included university students $(n=9), \mathrm{PhD}$ candidates and researchers $(n=17)$, teachers and translators $(n=10)$ and others $(n=11)$.

\section{Italian Use Score}

To assess the effect of HL use on accent in Italian and German, we developed an 'IUS' along the lines of Kupisch et al. (in press) by quantifying aspects of Italian use across the lifespan. This was done by attributing weighted scores to 20 different aspects of language use reported in a background questionnaire, which we grouped into the categories 'Italian Use at Home', 'Quality of Italian Use', 'Current Italian Use' and 'Time Spent in Italy' (explanations in Table 2). This resulted in a maximum score of $25(\mathrm{M}=16.9, \mathrm{SD}=3.6)$ for each participant. 


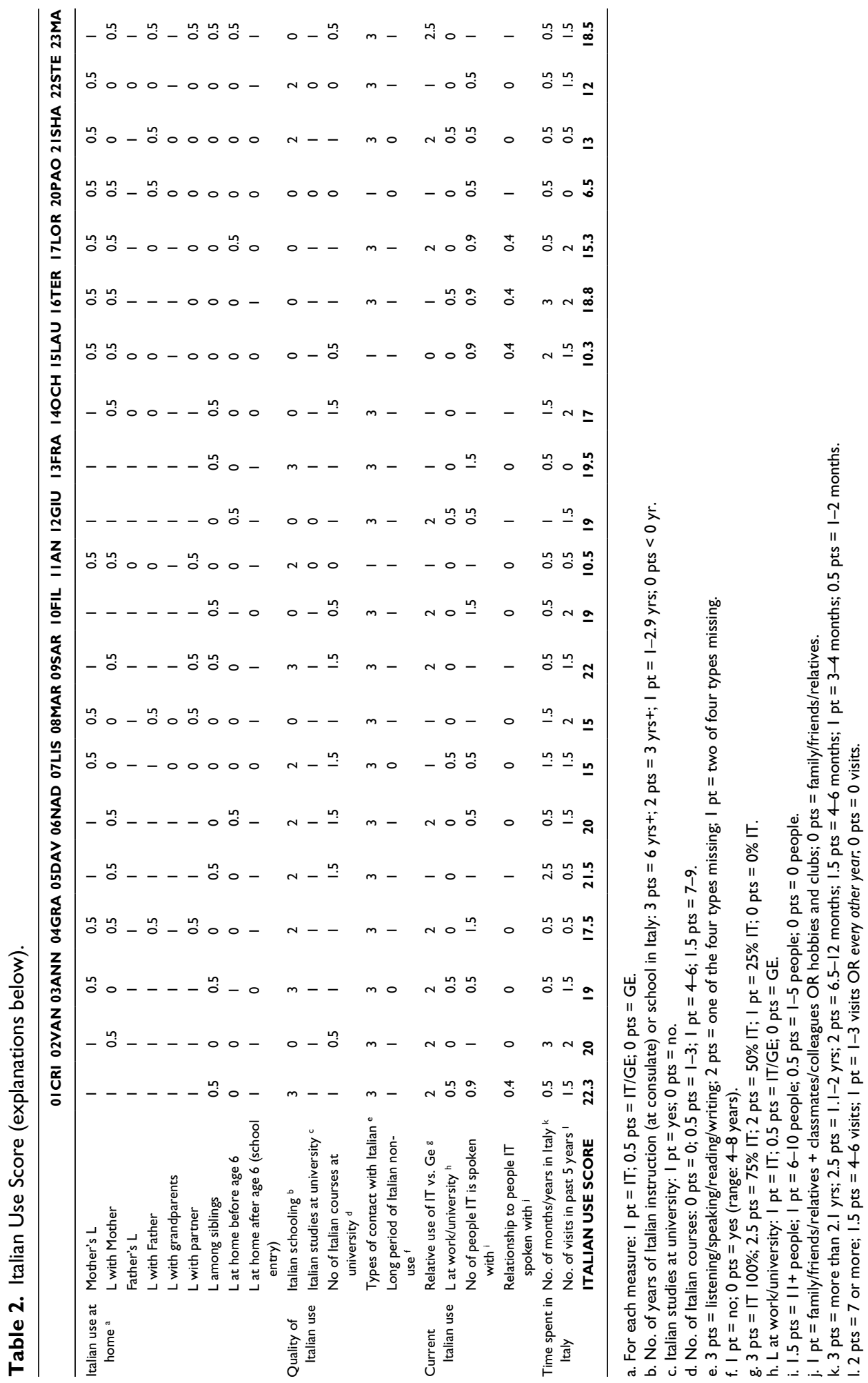




\section{Preparation of material}

The speech samples for both experiments were elicited during individual interviews conducted in Italian and German on separate days by means of a picture description task. The Italian task consisted of eight pictures showing aspects relating to every-day life in the countryside, entitled ' $n e l l a$ fattoria' ('on the farm'); the German picture task consisted of eight pictures showing a young couple visiting, for example, a park, a cinema and a bar (entitled 'Karl und Susie'). Participants were instructed to tell a story lasting approximately 1 minute that made reference to each object depicted. Next, we extracted one 10-second sample per speaker (+/- $150 \mathrm{~ms}$ to ensure syntactic completeness). The samples contained no morphosyntactic errors, and pauses longer than $150 \mathrm{~ms}$ were shortened using Audacity to ensure a comparable amount of material per sample. We decided to use semi-naturalistic speech over read speech or sentence repetition because we believe naturalistic speech is more reflective of participants' speech in real-life situations, while using a picture sequence ensures relative homogeneity of content and lexicon. Finally, the samples were integrated into two separate, self-directed experiments using the online software SoSci Survey (Leiner, 2014) and made available to raters on www.soscisurvey.com. The German-language experiment contained the 21 bilingual, 10 monolingual and $10 \mathrm{~L} 2$ samples of German, and all experimental material was in German. The Italian-language experiment contained the 21 bilingual, 10 monolingual and 10 L2 samples, and all experimental material was in Italian. The order of the samples was pre-defined and semi-randomized, and two randomizations existed per experiment (random selection).

\section{Procedure}

Firstly, the raters were required to provide anonymized background details to ensure they met the criteria for participation (i.e., native speakers of Italian or German with exposure to one language only before age 6), and to provide basic information on their language background, age and occupation. Next, the experimental procedure was explained. 'Foreign accent' was defined as any perceived divergence from a native speaker resulting not from the presence of regional varieties, but from the influence of another language (Derwing \& Munro, 2009). The raters were instructed to work in quiet surroundings and to use headphones, and completed an audio test to ensure they could hear the recordings. Finally, a training session with three ratings was completed. The actual rating procedure consisted of two steps: In Step (1), raters listened to the 10-second sample (one listen only) and judged whether they could detect a foreign accent (Yes or No). In Step (2), they indicated their degree of certainty from three options: certain, semi-certain, uncertain (see the experimental design in Figure 2). ${ }^{4}$ This step was included because, as suggested by Kupisch et al. (2014), raters are often less certain when listening to HSs' accents.

\section{Results}

\section{Analyses}

In our analyses below, we first report descriptive statistics illustrating the number of "no foreign accent' ratings by language group, then compare the bilinguals to the two control groups for perceived accentedness in their two languages, Italian and German (see also the descriptive results in the three right-most columns of Table 1). To this end, we performed mixed effects multiple logistic regression analyses (since speakers were classified as either foreign-accented or non-accented) with 'rated native' as the dependent variable and 'language group' as the predictor of interest (fixed factor). ${ }^{5}$ In the second step, we looked at the relative ability of the background predictors 'AoO' 


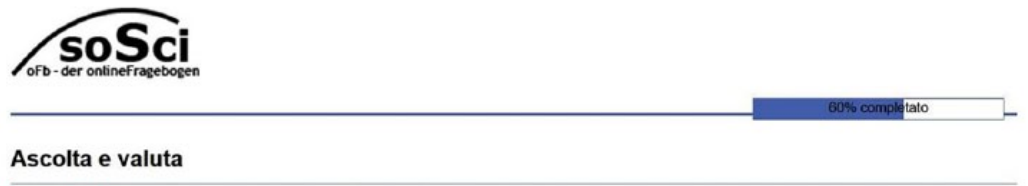

Importante: potrai ascoltare il file audio una volta soltanto!

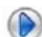

1. Senti un accento straniero?

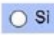

No

2. Quanto sei sicura/sicuro?

Figure 2. Experimental design for the Italian experiment.

(a)

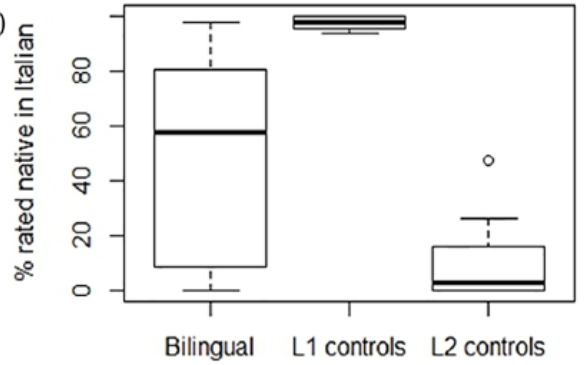

(b)

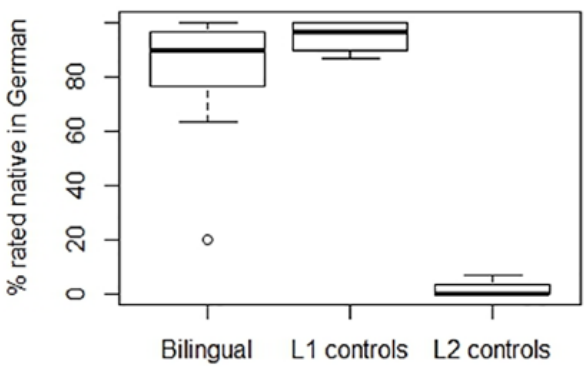

Figure 3. Boxplots displaying the \% of times rated native in Italian (a) and German (b). LI: first language; L2: second language.

(AoO in German was between 0 and 6 years and was treated as a continuous variable) and 'Italian Use' to predict perceived accent, first using basic correlational analyses, then using both variables together in multiple logistic regression. Finally, we present the results for the certainty ratings. In all regression analyses, 'items' and 'raters' were crossed random effect factors and, for each model, we tested whether adding random slopes for within-group random effects increased the fit of the model (Cunnings, 2012). ${ }^{6}$

\section{Accent rating results}

To provide an initial overview, we plotted the percentage of times each speaker was rated as non-accented in their two languages in Figure 3 by speaker group (Italian (a); German (b)). ${ }^{7}$ Figure 3 shows that the bilinguals were rated as non-accented more frequently in their ML German $(\mathrm{M}=87.9 \%, \mathrm{SD}=17.7)$ than in their HL Italian $(\mathrm{M}=50.8 \%, \mathrm{SD}=34.7)$. For the 

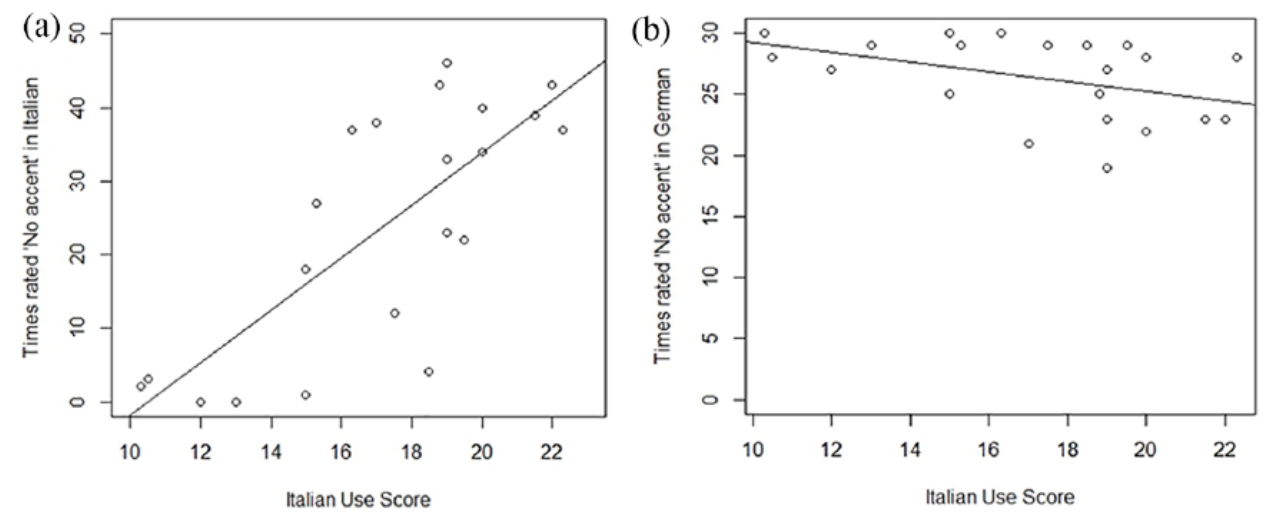

Figure 4. Times rated 'no accent' (y-axis) by 'Italian Use Score' ( $x$-axis) when speaking Italian (a) and when speaking German (b).

control groups, the L1 monolinguals were correctly identified as having 'no foreign accent' in $94 \%$ of ratings for the German experiment ( $\mathrm{SD}=4.9$ ), and in $97.2 \%$ of ratings for the Italian experiment $(\mathrm{SD}=2.3)$. The L2 speakers of German with Italian as their L1 were seldom rated as non-accented $(\mathrm{M}=10 \%, \mathrm{SD}=14.9)$, and the $\mathrm{L} 2$ speakers of Italian with German as their L1 were barely ever judged as accent free $(\mathrm{M}=1.3 \%, \mathrm{SD}=2.21)$. Taken as a measure of reliability, the ratings for the control groups illustrate that the raters were accurately able to determine the presence or absence of a foreign accent.

To ascertain the effect of language group, we performed logistic regression analyses. The results revealed no significant difference between the bilinguals and the L1 German controls in German $(\beta=1.02, \mathrm{SE}=0.55, z=1.85, p=.06)$, meaning that they were indistinguishable from their monolingual peers in their ML. In contrast, the difference between the bilinguals and the L1 Italians in Italian was highly significant $(\beta=4.92, \mathrm{SE}=0.93, z=5.24, p<.001)$, illustrated by the large range displayed in the Figure 3(a) for Italian. Finally, the bilinguals performed significantly better than the L2 controls in both languages, with the difference from the L2 speakers being larger for German $(\beta=-8.42, \mathrm{SE}=0.85, z=-9.87, p<.001)$ than for Italian $(\beta=-3.03, \mathrm{SE}=$ $0.95, \mathrm{z}=-3.18, p=.00144)$.

\section{Effects of Italian use and age of onset}

We first visualize the potential relations between 'AoO in German' and 'Italian Use' and the outcome variable 'perceived accent' using scatter plots and correlational analyses. The scatter plots in Figures 4 and 5 illustrate the linear relationships between 'IUS' (Figure 4) and AoO (Figure 5) and the 'times rated non-accented'. The numbers on the $y$-axis reflect the number of raters, which was higher for the Italian experiment.

For Italian use, Figure 4(a) shows a strong correlation with perceived nativeness in Italian, which was highly significant based on a Spearman's rank correlation for non-parametric data $\left(r_{s}=.72, p=.0001\right)$, while Figure 4(b) shows a moderate, negative correlation between Italian use and perceived nativeness in German (significant at $r_{s}=-.46, p=0.03$ ). For AoO in German, Figure 5(a) shows a weak negative relation between a later AoO in German and a stronger accent in German (a Kendall's Tau correlation test for non-parametric data with tied ranks was not significant: $r \tau=-0.31, p=0.07)$; Figure $5(\mathrm{~b})$ shows a moderate, positive relation between 

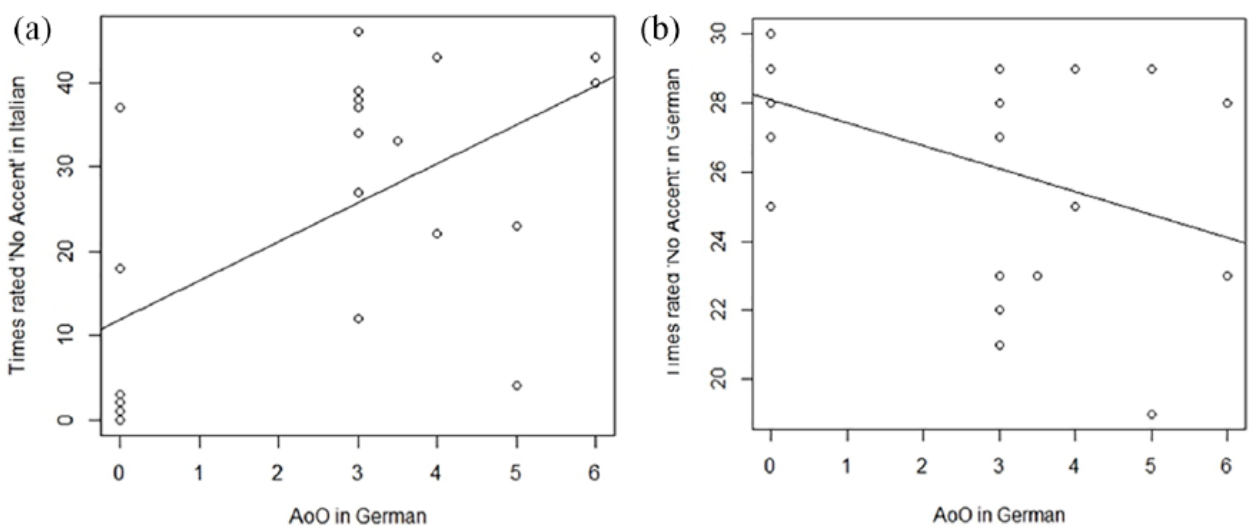

Figure 5. Times rated 'no accent' ( $y$-axis) by age of onset (AoO) in German ( $x$-axis) for German (a) and Italian (b).

a later $\mathrm{AoO}$ in German and a more native-sounding accent in Italian (significance at $r \tau=0.41$, $p=0.01)$.

Next, we perform multiple logistic regression with 'IUS' and 'AoO' as predictors and 'items' and 'raters' as crossed random effects to test the relative ability of the two predictors to explain the number of 'non-accented' ratings. Only one of the above correlations remained significant, namely the effect of Italian use on perceived nativeness in Italian $(\beta=0.53, \mathrm{SE}=0.15, z=3.46$, $p=.0005)$, indicating that the more Italian the bilinguals used, the more likely they were to be rated as native. No negative effect of Italian use was found for accentedness in German, despite the moderate negative correlation displayed in Figure $4(\beta=0.14, \mathrm{SE}=0.14, z=1.06, p=.28)$. Nor did 'AoO in German' have a significant effect on either language in the regression model (for German, $\beta=-0.32, \mathrm{SE}=0.28, z=-1.15, p=.24$; for Italian, $\beta=0.07, \mathrm{SE}=0.29, z=0.26$, $p=.78)$.

\section{Certainty ratings}

Recall that after identifying whether they could detect a foreign accent, the raters specified their level of certainty (certain, semi-certain or uncertain). Figure 6 displays the percentage of certain, semi-certain and uncertain ratings per language (German (a); Italian (b)) by speaker group. In the German experiment, the raters were 'certain' in $72.8 \%$ of the bilingual ratings, in $82.6 \%$ of the monolingual ratings and in $93 \%$ of the L2 ratings; in the Italian experiment, the raters were 'certain' in $58.4 \%$ of the bilingual ratings, in $82.1 \%$ of the monolingual ratings and in $74.2 \%$ of the L2 ratings.

Thus, the raters appeared least certain when judging the bilinguals in both experiments. Multiple regression analyses showed there was no significant difference between the bilinguals and the monolinguals in German $(\beta=0.09, \mathrm{SE}=0.05, d f=38.00, t=1.88, p=.06)$, but that there was a highly significant difference between the bilinguals and the monolinguals in Italian $(\beta=0.32, \mathrm{SE}=0.08, d f=38.00, t=3.85, p=.0004)$. In line with this observation, the difference between the bilinguals and the L 2 controls was highly significant in German $(\beta=0.19 \mathrm{SE}=0.05$, $d f=38.00, t=3.84, p=.0004)$, but only marginally significant in Italian $(\beta=0.16, \mathrm{SE}=0.08$, $d f=38.00, t=2.00, p=.052)$. Thus, the certainty ratings for the bilinguals patterned more closely with the German monolinguals in German, but with the L2 speakers in Italian. 
(a)

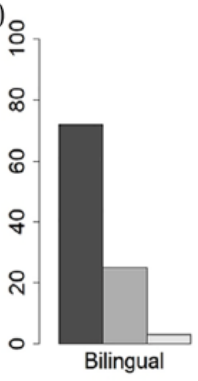

German

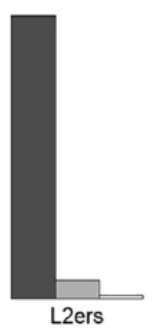

(b)

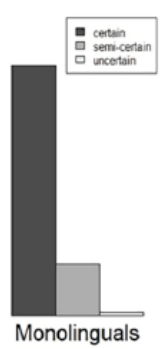

b)

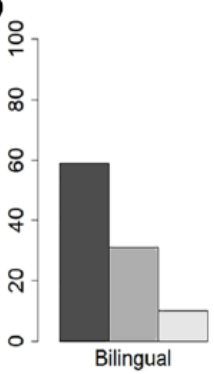

Italian

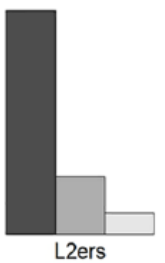

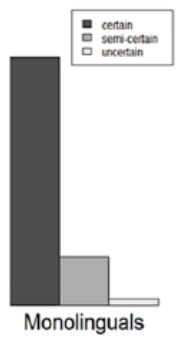

Figure 6. Rater certainty (\%) in the German experiment (a) and the Italian experiment (b).

\section{Discussion}

\section{The effects of AoO and Italian use}

In their ML, the Italian-German early bilinguals in this study were perceived as non-accented in $87.9 \%$ of ratings in German, with no statistical difference to the monolingual controls (94\%), and significantly more native-like than L2 speakers (10\%). 'AoO' and 'IUS' were negatively correlated with perceived nativeness in German, but neither predictor reached significance in a multiple regression model. In their HL Italian, the bilinguals were rated as non-accented in 50.8\% of ratings, significantly below the L1 monolingual controls (97\%) and significantly above the L2 controls (1.3\%). Correlational analyses showed positive relationships between both predictors and perceived nativeness in Italian; however, multiple regression indicated that 'IUS' was the only predictor to reach significance. The expectation that the HSs would be judged with less certainty than monolingual controls did not transpire for German, but it did for Italian. This parallels the result in Kupisch et al. (2014), whereby raters were less certain when judging HSs in their HL than when judging other speakers. The certainty ratings also parallel the accentedness ratings from the current study in aligning the bilingual speakers closely to the monolinguals in German, but closer to the L2 speakers in Italian.

It should not come as a surprise that the linear relationships that were apparent in correlational analyses (Figures 4 and 5) did not all stand up to multiple regression. When two variables are pitted against each other as predictors, relationships that were apparent between individual variables may disappear or give way to the variable with the higher explanatory power, which in this case was 'IUS' ${ }^{8}$ Moreover, as is well known in the literature on bilingualism, 'Age'- and 'Input/Use'related variables are often (partially) correlated with one another anyway, meaning that there is some overlap in the variance they explain. To control for collinearity, we applied a collinearity test to both predictors using the collin.fnc function from the language R package (Baayen, 2008, p. 200), and found medium collinearity with a condition value of 17.38 , which suggests these variables are correlated, but not severely. ${ }^{9}$ The fact that 'IUS' and 'AoO' are correlated is clear simply by looking at the descriptive data in the right-hand side columns in Table 1 . Here, we see that the percentage of native-like ratings in Italian is considerably lower for the $2 \mathrm{~L} 1$ speakers $($ mean $=18.54 \%, \mathrm{SD}=27.57$, range $=0-78 \%)$ than for the early L2 speakers (mean $=$ $67.02 \%, \mathrm{SD}=25.45$, range $=8.51-97.87 \%$ ). If we can accept, however, that AoO in German simply cannot be the cause of this difference per se, then there are two potential explanations (not mutually exclusive) for why this might be. Firstly, the years before age 3 are crucial for phonological development, and increased exposure during these years (since it is the only language a child hears) still shows up in the accents of final-state bilinguals. The other - perhaps more plausible - explanation is that the eL2s all had two Italian-speaking parents, whereas the eL2s had 
only one and, as a resulting, less exposure to Italian in the home context over the lifespan. Thus, we would argue that what appears prima facia to be an effect of AoO in German is in fact an effect of increased exposure to Italian, either before the age of 3, or across the lifespan.

\section{Discussion of results in light of other studies}

The bilinguals in this study received relatively high native-like scores in their HL (mean $=50.8 \%$ ), considerably above the German dominant HSs of Italian investigated in Kupisch et al. (2014), who were rated as non-accented in $30 \%$ of ratings. Instead, they are on par with the German-dominant HSs of French (49\%) from the same study, and with the Turkish HSs in Stangen et al. (2015; 48\%). As mentioned earlier, Kupisch et al. (2014) argued that the different outcomes for the French and Italian HSs could be best explained by their differential opportunities for HL exposure, which was higher for the former than for the latter. Our results lend weight to this hypothesis: not only did we find a strong and significant correlation between Italian use and perceived nativeness in the HL, but the fact the Italian HSs in this study performed so well compared to Italian HSs from North Germany may be a reflection of the much larger Italian-speaking community in South Germany. This hypothesis would also be in line with the high percentage of native-like ratings received by the Turkish HSs based in Hamburg, who happen to be situated in one of the largest Turkishspeaking communities in Western Europe. Finally, these results underscore what was already claimed by Stangen et al. (2015) and Kupisch et al. (2018), namely that accent in the HL is better predicted by use and opportunity for engagement than it is by the AoO of the ML. In summary, although it may be the case for child-aged bilinguals that introducing the ML earlier causes more phonological pressure on the HL than when it is introduced later (Kupisch, in press), this effect seems to have disappeared by adulthood - at least with regards to perceived global accent.

Turning now to the discussion of accent in the ML German. Our results lend weight to studies that have shown that HSs sound monolingual-like in their ML regardless of whether it is acquired simultaneously from birth or successively between the ages of 3 and 6 (e.g., Stangen et al., 2015; Kupisch et al., in press). These results may appear to be in contrast with studies that found detectable accents in the ML of speakers with an AoO below 6 (e.g., Abrahamson \& Hyltenstam, 2009; Flege et al., 1995), however, it should be stressed that those studies did not examine global accent in naturalistic speech. In Abrahamson and Hyltenstam (2009), advanced L2 speakers who had passed as native Swedish speakers in global measures no longer did so in more detailed scrutiny of accent, including VOT production and speech perception in noise; in Flege et al. (1995), samples were elicited using delayed sentence repetition, which perhaps renders different native-like ratings than naturalistic speech. In other words, listeners' perceptions of global accent do not necessarily correspond with more restricted measures of language production or perception. Finally, in contrast to studies that have shown negative effects of L1 use on the pronunciation of the earlyacquired L2 (e.g., Flege et al., 1997), the results of this study indicate no significant impact of Italian use on German, and are thus in line with findings of Kupisch et al. (2014).

The question remains as to why the German-Turkish early bilinguals in Kupisch et al. (2014) were rated as nativelike in their ML German in just $60 \%$ of ratings, while the bilinguals from the study by Kupisch et al. (2014) - and those from the current study - were rated on par with monolingual controls. Although attempting to generalize the results from one HS population to another is less than ideal, if we nevertheless apply the results from our analyses to the participants in Stangen et al. (2015), then it seems unlikely that the amount of Turkish use or the later AoO in German could explain this outcome. This leaves us with the proposal that Kiezdeutsch could have contributed to the bilinguals' perceived foreignness in German (Stangen et al., 2015), suggesting that this aspect warrants further investigation. Finally, one possibility that was already raised by 
Kupisch et al. (2014) is that there may be something about the phonetic-phonological properties of languages that makes it more difficult for speakers of certain language-pairings to acquire nativesounding accents, and certain accents may be perceived by listeners as more salient than others. However, further research would be needed to identify which properties exactly these could be.

\section{Conclusion}

Our study has shown that adult HSs of Italian in Germany are overall perceived as native in their ML, with no statistical difference to monolingual German speakers. While HSs have advantages over L2 speakers in their HL, perceived nativeness varies between individuals. Although a positive correlation was found between a later AoO in German and a more monolingual-like accent in Italian, this relation did not hold up in multiple regression analyses. Instead, HL use, operationalized as a composite score of experience-related variables, was a strong predictor of nativeness in Italian, and HL use had no negative impact on the ML. We interpret these results as evidence that accent in the HL of early bilinguals is determined by the amount of use of the HL itself, and not by age of acquisition of the ML.

\section{Acknowledgements}

We wish to thank Miriam Geiß, Stefano Quaglia, Simone Waitz and Sarah Zander for their valuable support during data collection.

\section{Declaration of conflicting interests}

The author(s) declared no potential conflicts of interest with respect to the research, authorship, and/or publication of this article.

\section{Funding}

The author(s) received no financial support for the research, authorship, and/or publication of this article.

\section{Notes}

1. Originally our sample consisted of 23 early bilinguals. Two were excluded from analyses as they were deemed non-native in German due to reasons other than accentedness (VP18 spoke Swiss-accented Standard German and VP19 had a slight stutter).

2. We agree with an anonymous reviewer that it would be interesting to look at the potential effect of the bilinguals' parents' origins on accent in Italian. However, we cannot draw any conclusions in this regard due to our small sample size and confounds with other variables. For example, given the fact that AoO correlates strongly with perceived nativeness in Italian, we would need to have an equal number of $2 \mathrm{~L} 1$ and early L2 speakers from each area. Currently, six out of seven 2L1 speakers had parents from North Italy, which would skew results.

3. Since they were born and grew up in Germany, they likely all had some exposure to German from birth. However, since exposure does not necessarily equal input, we follow Stangen et al. (2015) in specifying their 'first intensive contact' with the language, which usually corresponded with entry into kindergarten.

4. The two-step rating procedure was based on De Leeuw, Schmid, and Mennen (2010), although we follow the analytical procedure in Kupisch et al. (2014), which differs from that used in De Leeuw et al. (2010).

5. Our analytical procedure parallels that used by Kupisch et al. (2014), and differs from that in De Leeuw et al. (2010) and Stangen et al. (2015), whereby the two steps of the rating procedure were conflated onto a six-point scale with 'native/certain' and 'non-native/certain' on the extremes. We felt that using the binary variable (rather than converting the binary data to a six-point scale) more accurately reflected the data. It also meant we could look at the certainty data separately. However, we carried out preliminary analyses using the conflated six-point scale, and found a strong correlation between the aggregated 
variables 'mean accent strength' (six-point scale) and 'times rated accented', suggesting that similar results would be obtained using either variable.

6. The models using random slopes did not converge, presumably due to too little data.

7. For individual results see Table 1 .

8. One limitation to this interpretation is that our $\mathrm{AoO}$ variable is numerically less differentiated compared to the IUS, which possibly decreases its predictive power.

9. Following Baayen (2008), condition values that fall between 0 and 6 are regarded as evidence for no collinearity, while values falling around 15 are regarded as medium collinearity and values at 30 or above are regarded as potentially harmful collinearity.

\section{References}

Abrahamsson, N., \& Hyltenstam, K. (2009). Age of onset and nativelikeness in a second language: Listener perception versus linguistic scrutiny. Language Learning, 59(2), 249-306.

Ahn, S., Chang, C. B., DeKeyser, R., \& Lee-Ellis, S. (2017). Age effects in first language attrition: speech perception by Korean-English bilinguals. Language Learning, 67, 694-733.

Alderson, J. C. (2005). Diagnosing foreign language proficiency: The interface between learning and assessment. London: Continuum.

Baayen, R. H. (2008). Analyzing linguistic data: A practical introduction to statistics. Cambridge, UK: Cambridge University Press.

Bever, T. G. (1981). Normal acquisition processes explain the critical period for language learning. In K. C. Diller (Ed.), Individual differences and universals in language learning aptitude (pp. 176-198). Rowley: Newbury House.

Chang, C. B., \& Yao, Y. (2016). Toward an understanding of heritage prosody: Acoustic and perceptual properties of tone produced by heritage, native, and second language speakers of Mandarin. Heritage Language Journal 13(2), 134-160.

Chang, C. B., Yao, Y., Haynes, E. F., \& Rhodes, R. (2011). Production of phonetic and phonological contrast by heritage speakers of Mandarin. The Journal of the Acoustical Society of America, 129(6), 3964-3980.

Cunnings, I. (2012). An overview of mixed-effects statistical models for second language researchers. Second Language Research, 28(3), 369-382.

De Leeuw, E., Schmid, M. S., \& Mennen, I. (2010). The effects of contact on native language pronunciation in an L2 migrant setting. Bilingualism: Language and Cognition, 13(1), 33-40.

Derwing, T. M., \& Munro, M. J. (2009). Putting accent in its place: Rethinking obstacles to communication. Language Teaching and Research, 42(4), 476-490.

Flege, J. E. (1984). The detection of French accent by American listeners. Journal of the Acoustical Society of America, 76, 692-707.

Flege, J. E., Frieda, A., \& Nozawa, T. (1997). Amount of native-language (L1) use affects the pronunciation of an L2. Journal of Phonetics, 25, 169-186.

Flege, J. E., Munro, M. J., \& MacKay, I. R. A. (1995). Factors affecting strength of perceived foreign accent in a second language. Journal of the Acoustical Society of America, 97, 3125-3134.

Flores, C., \& Rato, A. (2016). Global accent in the Portuguese speech of heritage returnees. Journal of Heritage Language, 13(2), 161-183.

Fox, A. V. (2007). Kindliche Aussprachestörungen. Idstein: Schulz-Kirchner.

Grabe, E., Post, B., \& Watson, I. (1999). The acquisition of rhythmic patterns in English and French. In Proceedings of ICPhS 1999 (pp. 1201-1202). San Francisco: ICPhS.

Grijzenhout, J., \& Joppen-Hellwig, S. (2002). The lack of onsets in German child phonology. In I. Lasser (Ed.), The Process of Language Acquisition (Proceedings of GALA'99) (pp. 319-339). Frankfurt, Germany: Peter Lang Verlag.

Kehoe, M., \& Lleó, C. (2003). The acquisition of phonological vowel length. A longitudinal analysis of three German-speaking children. Journal of Child Language, 30(3), 527-556.

Khattab, G., \& Al-Tamimi, J. (2015). The acquisition of Gemination in Lebanese-Arabic children. In The Scottish Consortium for ICPhS 2015 (Ed.), Proceedings of the 18th international congress of phonetic sciences (Paper Number 870, pp. 1-5). Glasgow, UK: The University of Glasgow. 
Kunnari, S., Nakai, S., \& Vihman, M. M. (2001). Cross-linguistic evidence for the acquisition of geminates. Psychology of Language and Communication, 5(2), 13-24.

Kupisch, T. (in press). 2L1 simultaneous bilinguals as heritage speakers in morpho-syntax and phonology. In M. Schmid, \& B. Köpcke (Eds.), The Oxford handbook of language attrition. Oxford: Oxford University Press.

Kupisch, T., Barton, D., Klaschik, E., Lein, T., Stangen, I., \& van de Weijer, J. (2014). Foreign accent in adult simultaneous bilinguals. The Heritage Language Journal, 11(2), 123-150.

Kupisch, T., \& Lleó, C. (2017). Voice onset time in German-Italian simultaneous bilinguals. In M. Yavas, M. Kehoe, \& W. Cardoso (Eds.), Romance-Germanic bilingual (pp. 79-98). Phonology, Sheffield: Equinox.

Kupisch, T., Lloyd-Smith, A., \& Stangen, I. (in press). Perceived global accent in Turkish heritage speakers in Germany: Exposure and use are more important than AoO.

Lein, T., Kupisch, T., \& van de Weijer, J. (2016). VOT and global foreign accent in German-French simultaneous bilinguals during adulthood. International Journal of Bilingualism, 20(6), 732-749.

Leiner, D. J. (2014). SoSci Survey (Version 2.5.00-i) [Computer software]. Retrieved from http://www.soscisurvey. com.

Lleó, C. (2003). Child prosody and filler syllables: Looking into Spanish through the optimal window of acquisition. In S. Montrul, \& F. Ordóñez (Eds.), Linguistic theory and language development in hispanic languages. Papers from the 5th hispanic linguistics symposium and the 4th conference on the acquisition of Spanish and Portuguese (pp. 229-253). Somerville, Mass.: Cascadilla Press.

Munro, M. J, Flege, E., \& Mackay I. R. A. (1996). The effects of age of second language learning on the production of English vowels. Applied Psycholinguistics, 17, 313-334.

Nagy, N., \& Kochetov, A. (2013). Voice onset time across the generations: A cross-linguistic study of contact-induced change. In P. Siemund, I. Gogolin, M. Schulz, \& J. Davydova (Eds.), Multilingualism and language contact in urban areas (pp. 19-38). Amsterdam: Benjamins.

Paradis, M. (2009). Declarative and procedural determinants of second languages. Amsterdam, Philadelphia: Benjamins.

Stangen, I., Kupisch, T., Proietti Erguen A. L., \& Zielke, M. (2015). Foreign accent in heritage speakers of Turkish in Germany. In H. Peukert (Ed.), Transfer effects in multilingual language development (pp. 87-108). Amsterdam: Benjamins.

Stoehr, A. (2018). Speech Production, Perception, and Input of Simultaneous Bilingual Preschoolers: Evidence from Voice Onset Time (Doctoral dissertation), Radboud University Nijmegen, The Netherlands.

Sundara, M., \& Polka, L. (2008). Discrimination of coronal stops by bilingual adults: The timing and nature of language interaction. Cognition, 106, 234-258.

Wiese, H. (2012). Kiezdeutsch: Ein neuer Dialekt entsteht. München: C.H. Beck.

Yeni-Komshian, G. H., Flege, J. E., \& Liu, S. (2000). Pronunciation proficiency in the first and second languages of Korean-English bilinguals. Bilingualism: Language and Cognition, 3(2), 131-149.

\section{Author biographies}

Anika Lloyd-Smith is a PhD candidate in her final year at the University of Konstanz. She completed her studies in Auckland and Hamburg in the field of Multilingual Educational Linguistics, with a focus on third language acquisition. She has worked in Germany and in New Zealand as an English language teacher, and her research concerns the acquisition of English in multilingual contexts.

Marieke Einfeldt is a PhD candidate at the University of Konstanz. She holds a BA in Italian and a MA in Multilingual Educational Linguistics, both earned at the University of Hamburg. Her main research interest lies in the field of multilingual first language acquisition with a focus on phonology.

Tanja Kupisch is Full Professor in Linguistics at the University of Konstanz, and Associated Professor at the Arctic University of Norway. She has worked as a researcher and teacher at the universities of Hamburg, Calgary, McGill and Lund, focusing on various aspects of language acquisition. Her research areas include child bilingualism, adult L2 acquisition, bilectal language acquisition, L3 acquisition, language attrition, and language dominance, and her work is concerned with various aspects of nominal syntax and pronunciation. Her publications have appeared in journals such as Bilingualism: Language and Cognition, International Journal of Bilingualism, Linguistic Approaches of Bilingualism, and Second Language Research. 